\title{
Thermal expansibility of 310 s steel-based PVD coating in presence of metastable phase
}

\author{
Barbara Kucharska \\ Czestochowa University of Technology, Armii Krajowej 19, 42-200 Częstochowa, Poland \\ bratek@wip.pcz.pl
}

Keywords: iron-chromium-nickel coating, thermal expansion, magnetron sputtering.

\begin{abstract}
The paper discusses the examination of the thermal expansibility of a coating composed of the austenitic steel $310 \mathrm{~S}$ using the X-ray diffraction technique. Temperature measurements were made in the temperature interval of $\mathrm{T}_{\mathrm{amb}} \div 200^{\circ} \mathrm{C}$, in which the transition of the metastable bcc phase forming the as-applied coating into an fcc-type phase occurred in the coating. The values of the coefficients of thermal expansion of both phases were determined by using the weighted average of the intensities of diffraction reflections recorded. The values of the coefficients of thermal expansion of both phases within the entire examination range $\left(\mathrm{T}_{\mathrm{amb}} \div 200^{\circ} \mathrm{C}\right)$, determined as the weighed averages with the weight allowing for the intensities of individual reflections, were found to be, respectively, $0.9 \cdot 10^{-5} \mathrm{~K}^{-1}$ for the bcc phase and $1.5 \cdot 10^{-5} \mathrm{~K}^{-1}$ for the fcc phase, and by approx. $0.1 \cdot 10^{-5} \mathrm{~K}^{-1}$ lower than the values typical of the phases of austenite and ferrite in conventional steels.
\end{abstract}

\section{Introduction}

The PVD methods offer wide possibilities for producing coatings of complex chemical composition. In these methods, the atoms of components, being sputtered in the form of plasma, are deposited simultaneously on the substrate to form a uniform chemical composition independent of the individual melting points of the components involved [1]. Coatings deposited by these methods are characterized by a specific structural construction and frequently a metastable phase composition [2,3]. Phase metastability was found e.g. in coatings deposited by sputtering corrosionresisting chromium-nickel steels of the 304, 316 and 310 types [4-9]. After being deposited, PVD coatings exhibit good adhesion to the substrate. However, similarly as for any other coatings, under elevated temperature operation conditions their adhesion depends on the correlation between the coefficients of thermal expansion of the coating itself and the substrate used. For the determination of the coefficients of thermal expansion of coatings the X-ray diffraction method is useful. This method enables the determination of temperature changes in phases, as related to individual crystallographic plane families, which is important especially in the description of metastable structures [10-12].

\section{Experiment}

Material. The subject of the investigation were coatings applied by sputtering the commercial austenitic steel $310 \mathrm{~S}$ and additionally pure $\mathrm{Al}$ and Ir. As a result, a coating of a thickness of $8.75 \mu \mathrm{m}$ and of the following chemical composition (at\%) was obtained: Fe 50.3, Cr 26.6, Ni 16.5, Si 1.2, $\mathrm{Mn} 1.2$, Al 4.0, Ir 0.3. The coating was deposited on a substrate of steel 310S, which had been polished on cloths and then ion etched in the chamber of a B-901 (Hoch Vakuum Dresden) magnetron before deposition. In the deposition process, the argon pressure was $5 \mathrm{~Pa}$ and the polarization potential was equal to $-50 \mathrm{~V}$.

Methodology. The coating in an as-coated condition was subjected to diffractometric measurements on a Seifert 3003TT apparatus equipped with a heating device featuring electronic temperature control, whose description and characterization is provided in work [13]. The measurements were made in situ within the temperature interval of $\mathrm{t}_{\mathrm{amb}} \div 200^{\circ} \mathrm{C}$. The measurement 
temperature was varied with a step of $10^{\circ}$, after which the specimen was held at that temperature for approx. 1 minute for the temperature to stabilize, and then the measurement was started. The measurement duration at each soaking temperature was 30 minutes. Only for the measurement at $70^{\circ} \mathrm{C}$ did the soaking last $24 \mathrm{hrs}$. Diffractions were made in an angle range of $2 \theta=40 \div 135^{\circ}$ using the radiation of $\mathrm{K}_{\alpha} \mathrm{Co}(0.17902 \mathrm{~nm})$.

\section{Results}

Phase Composition. In the diffraction pattern of a coating in an as-deposited condition, the occurrence of two strong reflections (110) and (211) from a bcc-type phase different from the phase of the steel used for the targets was found (Fig. 1). A reflection corresponding to an fcc-type phase was also recorded. However, due to the fact that in the symmetrical XRD measurement geometry used, starting from an $\theta$ angle of approx. $9^{\circ}$, the radiation penetrates through the whole coating, this reflection was assumed to have come from the austenitic substrate. Heating up of the specimen with the coating to higher temperatures caused a steady increase in the intensity of reflection (111) from



Fig. 1. Diffraction patterns of coatings as recorded at different temperatures. 
the fcc phase. In addition, new reflections appeared - at $40^{\circ} \mathrm{C}$, reflection (200), and starting from $70^{\circ} \mathrm{C}$ also reflection (220) occurred. As those reflections were not recorded on the initial specimen, it can be assumed that themselves and reflection (111) are both the result of transition of the bbc phase into the fcc phase. Reflection (220) occurred after a soaking time prolonged compared to the other soaking times, which is indicative of the effect of both temperature and time on this transition. After cooling the coating to room temperature the fcc reflections wasn't recorded in the diffraction pattern (Fig.2).

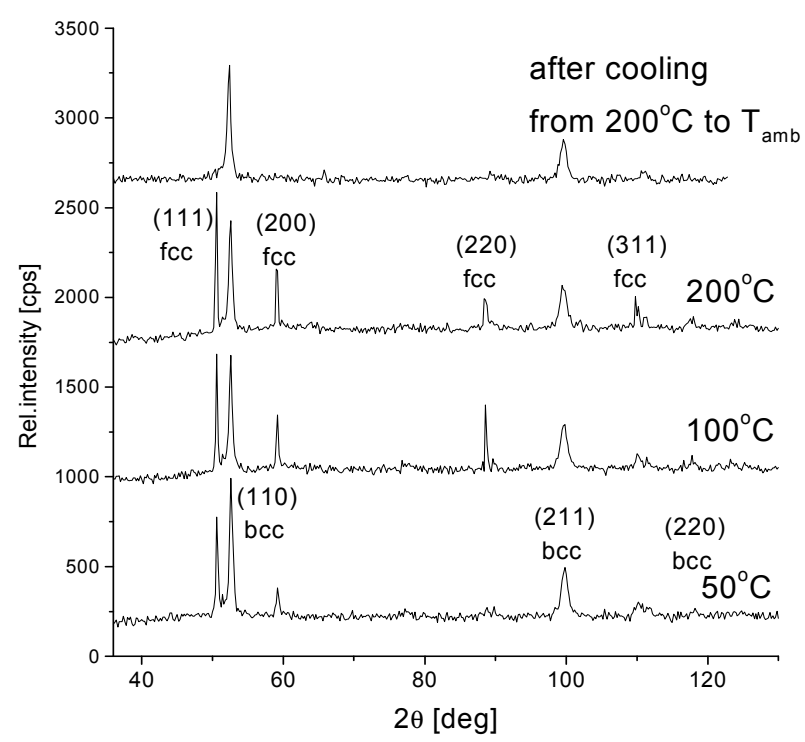

Fig. 2. Diffraction patterns of coatings as recorded at temperatures.

Intensity of reflections. Figure 3 compares the integral intensities $J_{\text {Net }}$ of all recorded reflections from each phase, as determined after prior describing the reflections with the pseudo-Voight curve using the Analyze software. A distinct, steady increase in the intensity of all reflections from the fcc phase with temperature was found. Only in the case of reflection (220) did the intensity reach a maximum at a temperature of approx. $130^{\circ} \mathrm{C}$, upon which it progressively decreased. The integral intensity of the bcc phase reflections decreased with increasing temperature.
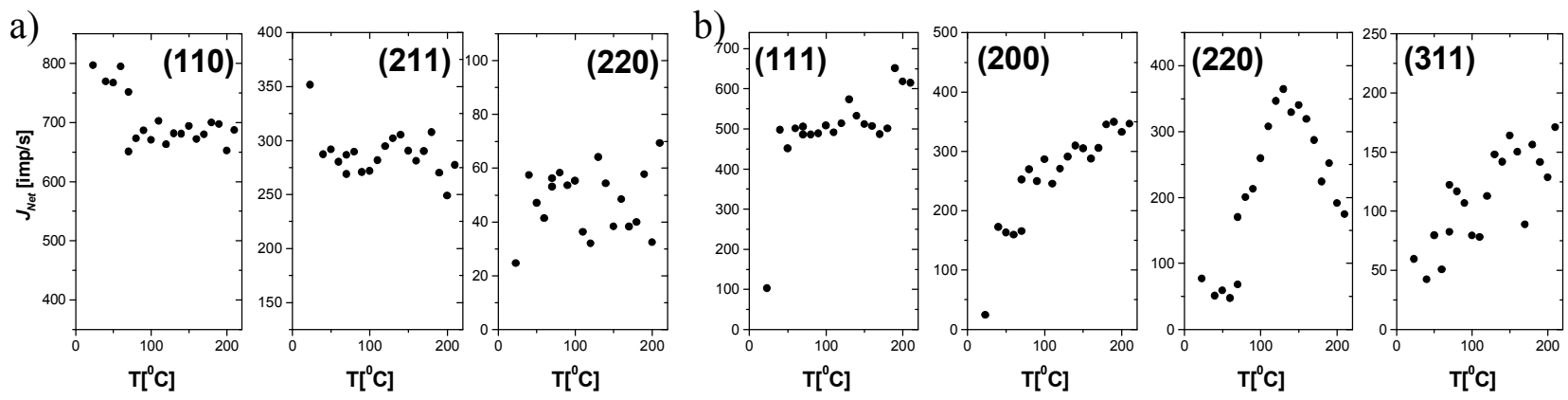

Fig. 3. Intensities of X-ray reflections, as recorded at different temperatures from phase a) bbc and b) fcc.

Lattice parameters. From all of the reflections recorded, increasing interplanar distance in both phases with increasing measurement temperature was noted (Fig. 4). The interplanar distance increase coefficients are shown on the linear fit segments. It was found that the least coefficient described the temperature dependence of the distance $d_{\mathrm{hkl}}$ of planes (211) in the metastable phase bcc. 
Based on the slopes of the linear fit $d_{h k l}^{T}=b \cdot T+d_{0}$, the coefficients of thermal expansion $\alpha^{h k l}$ of each of the phases in the directions perpendicular to particular lattice planes were calculated according to Eq. 1. The first term in Eq. 1 corresponds to the linear fit slope $b$ in Fig. 3.

$$
\alpha_{h k l}=\frac{d_{h k l}^{T}-d_{o}}{d_{o} \cdot \Delta T}=\frac{b}{d_{0}}
$$

where: $d_{h k l}^{T}$ - interplanar distance at the temperature $\mathrm{T}[\mathrm{nm}], d_{o}$ - interplanar distance as determined at ambient temperature [nm], $\Delta T$ - difference the measurement and ambient temperatures [K].
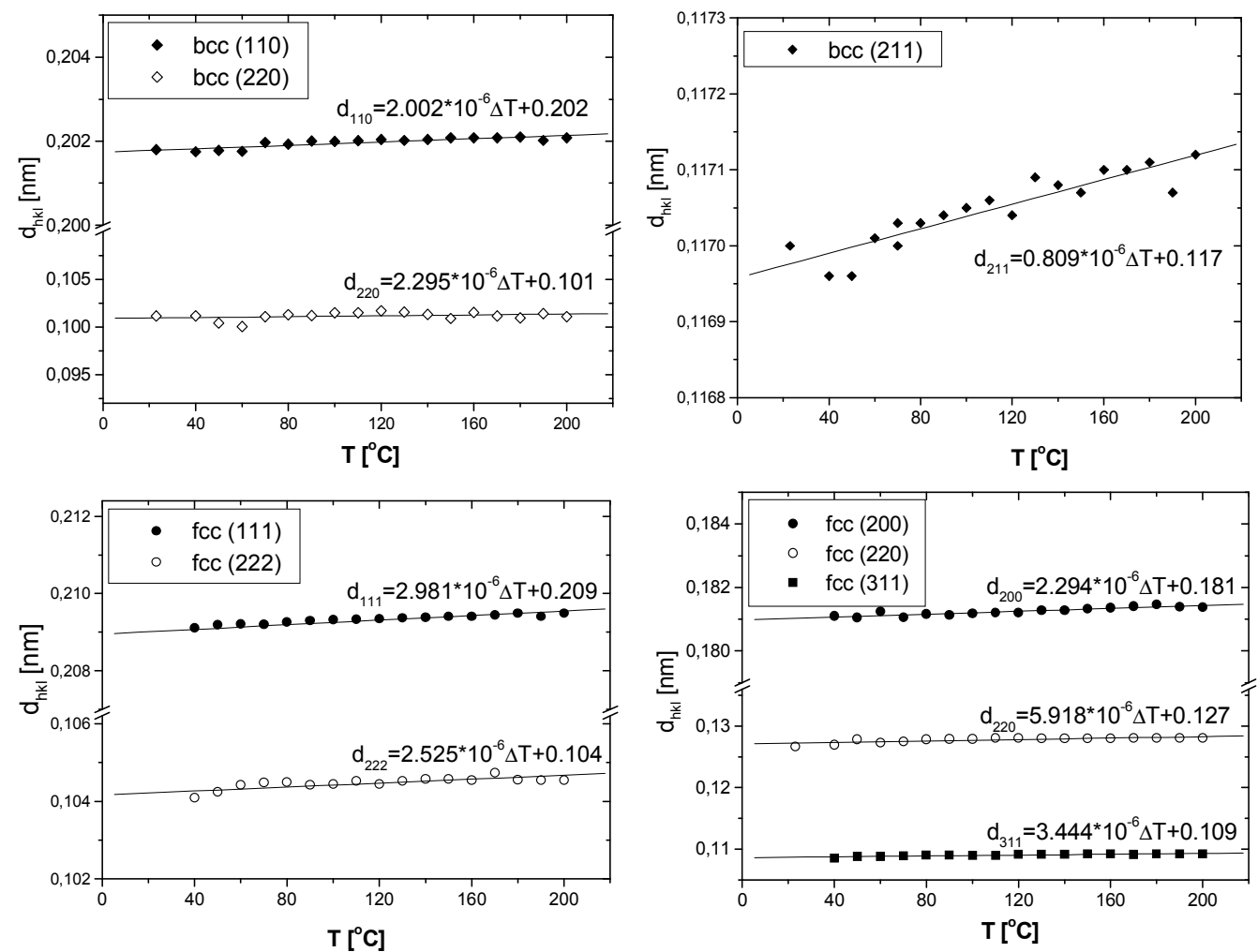

Fig. 4. The interplanar distance $d_{h k l}$ as a function of temperature for $\left.a, b\right)$ bcc phase and $c, d$ ) fec phase.

Thus obtained values of the coefficient of thermal expansion in the direction perpendicular to particular planes, $\alpha_{\mathrm{hkl}}$, and their arithmetical mean, $\alpha_{\mathrm{av}}$, are given in Table 1.

Table 1. Coefficients of thermal expansion of the phases bcc and fcc in the directions perpendicular to the lattice planes $\left(\alpha_{\mathrm{hkl}}\right)$, their arithmetical means $\left(\alpha_{\mathrm{av}}\right)$, and the weighted averages of reflection intensities $\left(\alpha^{I}\right)$.

\begin{tabular}{|c|c|c|c|c|c|c|c|c|}
\hline Phase & \multicolumn{3}{|c|}{ bcc } & \multicolumn{5}{c|}{ fcc } \\
\hline Plane & 110 & 211 & 220 & 111 & 200 & 220 & 311 & 222 \\
\hline$\alpha_{\mathrm{hkl}},\left[\mathrm{K}^{-1}\right]$ & $0.99 \cdot 10^{-5}$ & $0.69 \cdot 10^{-5}$ & $1.14 \cdot 10^{-5}$ & $1.43 \cdot 10^{-5}$ & $0.63 \cdot 10^{-5}$ & $2.32 \cdot 10^{-5}$ & $1.82 \cdot 10^{-5}$ & $1.21 \cdot 10^{-5}$ \\
\hline$\alpha_{\mathrm{av}},\left[\mathrm{K}^{-1}\right]$ & \multicolumn{3}{|c|}{$1.28 \cdot 10^{-5}$} \\
\hline$\alpha^{I},\left[\mathrm{~K}^{-1}\right]$ & \multicolumn{3}{|c|}{$0.94 \cdot 10^{-5}$} & \multicolumn{5}{c|}{$1.51 \cdot 10^{-5}$} \\
\hline
\end{tabular}

Knowing the mean values of the linear thermal expansion coefficient and the intensity of reflections coming from the reflection-generating planes, the averaged thermal expansibility of the ferritic and 
the austenitic phases was calculated as the weighted average, taking into account the integral intensity of individual reflections, $\sum I_{h k l}^{\text {Net }}$, in relation to the overall (total) intensity of all reflections from a given phase, $\sum I^{\text {Net }}$. The calculations of the coefficients $\alpha^{I}$ corresponding to the overall thermal expansibility of the crystalline lattice, as made according to Eq. 2, are also provided in Table 1.

$$
\alpha^{I}=\frac{\sum\left(\alpha_{h k l} \cdot \sum_{h k l} I_{h k l}^{N e t}\right)}{\sum I^{N e t}}
$$

To illustrate the effect of the temperature range used for determining the thermal expansion coefficients, calculations acc. to Eq. 1 were also performed for different temperature ranges in such a manner that the origin of a temperature range always corresponded to ambient temperature $\left(23^{\circ} \mathrm{C}\right)$, with the temperature being increased up to the end of the range. A graphical representation of the obtained coefficients as a function of the measurement range is shown in Fig. 5. It was found that the coefficients of thermal expansion of the fcc phase, as determined for successive temperature ranges, approached asymptotically from higher values to the standard value of the thermal expansion coefficient for the solid austenitic steel AISI 310S (the broken line in Fig. 5). The values of the linear coefficient of thermal expansion of the bcc phase remain below the level characteristic of austenitic steel and are close to the thermal expansion coefficient for ferritic steels $\left(\alpha \approx 1.0 \cdot 10^{-5} \mathrm{~K}^{-}\right.$ ${ }^{1}$ ). These values, after a small increase in the range of up to $70^{\circ} \mathrm{C}$, show a slightly decreasing tendency in broader temperature ranges.
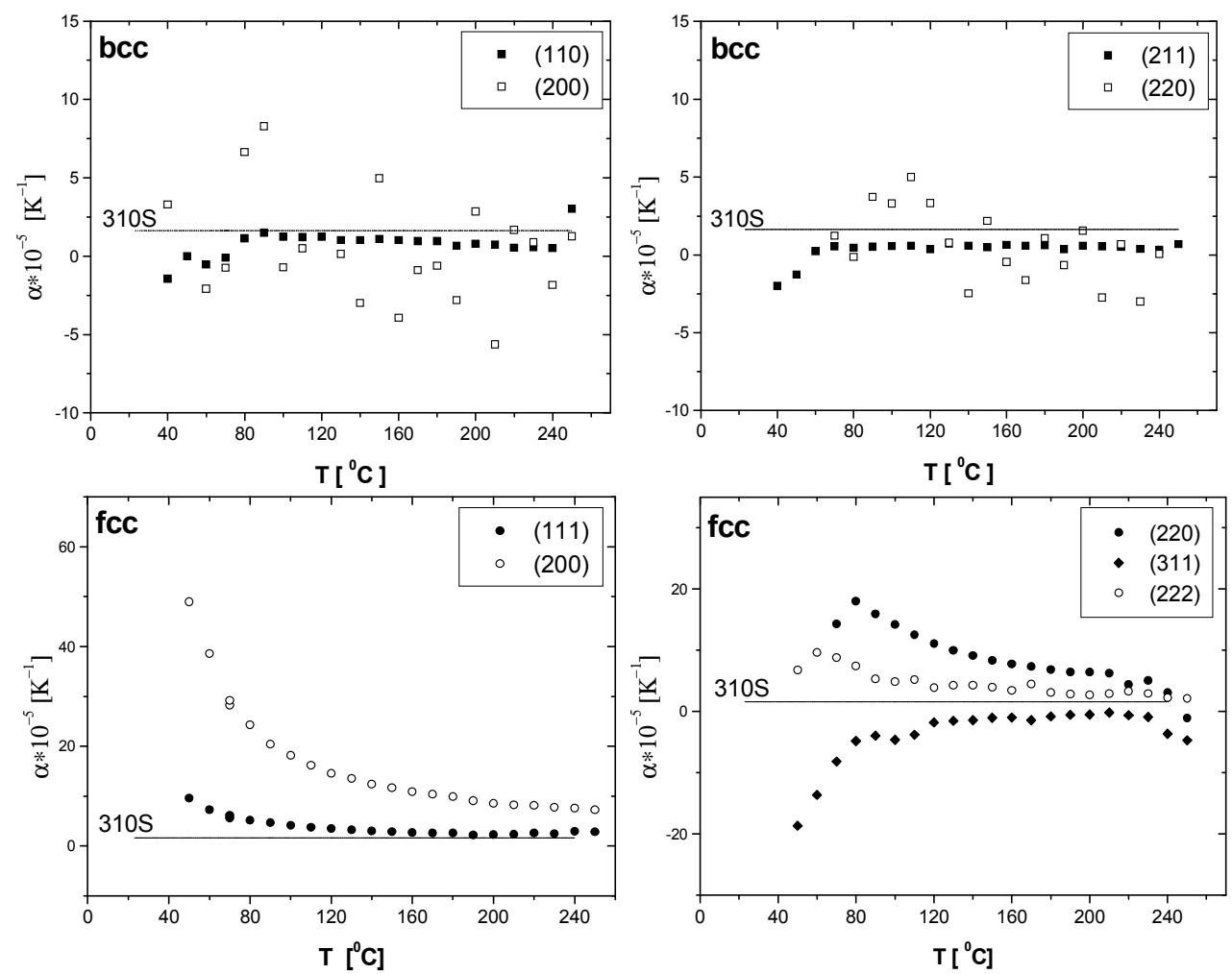

Fig. 5. Values of the thermal expansion coefficients for the: a,b) bcc phase, and c,d) fcc phase, as a function of the $\mathrm{T} \div \mathrm{T}_{\mathrm{amb}}$ temperature range. Each point in the diagrams represents the linear expansion coefficient for a different temperature range, namely: the first point corresponds to the range of $23 \div 40^{\circ} \mathrm{C}$, the second point to the range of $23 \div 50^{\circ} \mathrm{C}$, etc. 


\section{Summary}

The PVD coating produced by magnetron sputtering of steel $310 \mathrm{~S}$ and doped with additions of Al and Ir is built of a bcc-type metastable phase which, at elevated temperature, undergoes phase transition into the fcc phase, being typical of the conventional steel containing approx. $20 \% \mathrm{Ni}$. The thermal expansibility of both phases varies with increasing temperature range adopted for the investigation, in which the initial temperature is ambient temperature. For the fcc phase formed as a result of the phase transition, the thermal expansion coefficient decreased with increasing temperature range, approaching asymptotically the standard value for the conventional steel $310 \mathrm{~S}$ $\left(1.6 \cdot 10^{-5} \mathrm{~K}^{-1}\right)$. The coefficient of thermal expansion of the metastable phase bec was close to that of ferritic steel, and showed a slight decreasing tendency in the temperature range of $\mathrm{T}_{\mathrm{amb}} \div \mathrm{T}\left(>70^{\circ} \mathrm{C}\right)$. The values of the thermal expansion coefficients of both phases in the investigation range $\left(\mathrm{T}_{\mathrm{amb}} \div 200^{\circ} \mathrm{C}\right)$, determined as the weighted averages with the weight allowing for the intensity of individual reflections, amounted to, respectively, $0.9 \cdot 10^{-5} \mathrm{~K}^{-1}$ for the bcc phase and $1.5 \cdot 10^{-5} \mathrm{~K}^{-1}$ for the fcc phase, being by $0.1 \cdot 10^{-5} \mathrm{~K}^{-1}$ lower than the values typical of the austenite and the ferrite phases in conventional steels.

\section{References}

[1] A.Kinbara, E.Kusano and I.Kondo: Vacuum Vol.51, No.4 (1998), p. 475

[2] R Messier: J.Vacuum Sci.Technol. A 18(4), Jul/Aug 2000, p. 1538

[3] R.Messier, A.P.Giri and R.A.Roy: J.Vacuum Sci. Technol. A 2(2) Apr.-June 1984, p. 500

[4] R.I.Bates, R.D.Arnell: Surface and Coating Technol. 89 (1997), p. 204

[5] Z.Liu., G.Wang and W.Gao: Mater. Charact. 54 (2005), p. 466

[6] K.L.Dahm, P.A.Dearnley: Surface Engin. Vol.12, No.1 (1996), p. 61

[7] N.Merakeb, J.-P.Eymery, A.Finidiki, Ph.Goudeau and B.Bouzabata: Mater. Sci. 58 (2004), p. 711

[8] A.Di Cicco, M.Berrettoni, S.Stizza and E.Bonetti: Physica B 208\&209 (1995), p. 547

[9] A.Bourjot, M.Foos and C.Frantz: Surface and Coating Technol. 43/44 (1990), p. 533

[10] S.Inoue, T.Saeki, H.Uchida, K.Koterazawa and M.Iwasa: Vacuum 66 (2002), p. 257

[11] S.Harjo, Y.Tomota, M.Ono: Acta Mater. Vol. 47, No. 1 (1999), p. 353

[12]B.Kucharska, Mater. Sci - Poland, Vol.26, No.1 (2008), p. 181

[13]B.Kucharska, Z.Nitkiewicz: Inżynieria Materiałowa 6 (166) (2008), p. 1072 